\title{
Coin-operated Back Rub Machine
}

\author{
Fenglan Wang \\ School of Mechanical Engineering, Shenyang \\ University \\ Shenyang Liaoning, China \\ e-mail:flwang1965@sina.com
}

\author{
Bo Gao \\ Shenyang University \\ Shenyang Liaoning, China \\ e-mail: 497601981@qq.com
}

\begin{abstract}
In this design, facing the defects of manual back rub, bold structure innovation design is carried out in the coin-operated back rub machine to replace the human arms with mechanical arms. It is simple in structure, convenient in operation and safe in application; meanwhile, the efficiency of back rub is improved.
\end{abstract}

Keywords-Back Rub; Mechanical Arm; Efficiency; Coinoperated

\section{INTRODUCTION}

After investigation, it has been found out that in China, back rub machine is still a blank and it is all done by manual work. Manual back rub is a waste of time and strength and there are still many people who are dissatisfied with the service. The strength each person can tolerate is different, therefore, the feeling of back rub is different. However, a back rub machine can meet the various demands in strengths of different people. People have different emotions in their daily lives, and their emotions affect their behavior. But back rub machine owns different strengths to satisfy different people.

In this study, the back rub machine is recognized by most people, and it is simple in structure, convenient in operation and easy to maintain. In daily lives, some people may be overnice and don' $t$ like others to help rub their backs, but they won' thate a machine, and the back rub machine will not shut down due to various causes. The technological innovation of this invention is that with advancements in science and technology and social development, people care more about clean and tidy. And shower and back rub becomes part of life. However, when showering alone, it is difficult to clean the back. However, an automatic back rub machine helps solve the problem, making life happier.

\section{THE REALIZATION OF COIN-OPERATED BACK RUB MACHINE}

In this design, the whole mechanical drive system is fixed in one tank. And then the tank is fixed in the wall with only the slot machine and mechanical arms outside the wall. Once the coin is put in, the machine starts work with power on.

\author{
Anping Li \\ School of Mechanical Engineering, Shenyang \\ University \\ Shenyang Liaoning, China \\ e-mail: name@xyz.com
}

\section{DETERMINATION AND DESCRIPTION OF DESIGN SCHEME}

First, As is shown in Fig .1, the invention includes opening (1), tank cover (2), slot machine (3), tank (4), belt pulley (5), 1st electric motor (6), belt pulley (7), main shaft (8), cam (9), lower arm (10), spring (11), 2nd reciprocating motor (12), pinion (13), gearwheel (14), upper arm (15), upper tank cover (16), bearing (17), and arm (18). Firstly, an opening (1) is lined off in tank cover (2), and palm 18 is stretched from opening 1; slot machine 3 is fixed on tank cover 2 and connected with electric motor 6; when coin is put in, start electric motor 6 to connect the machine with electricity. Driven by belt pulleys 5 and 7 , the main shaft 8 begins rotating, making cam 9 rotate, and thus, arm 10 moving up and down. With PLC control, electric motor 6 stops working and motor 12 starts, thus, pinion makes the gearwheel rotate. Since the gearwheel is fixed on the upper arm, the palm can move from right to left to finish the whole process of back rub. 


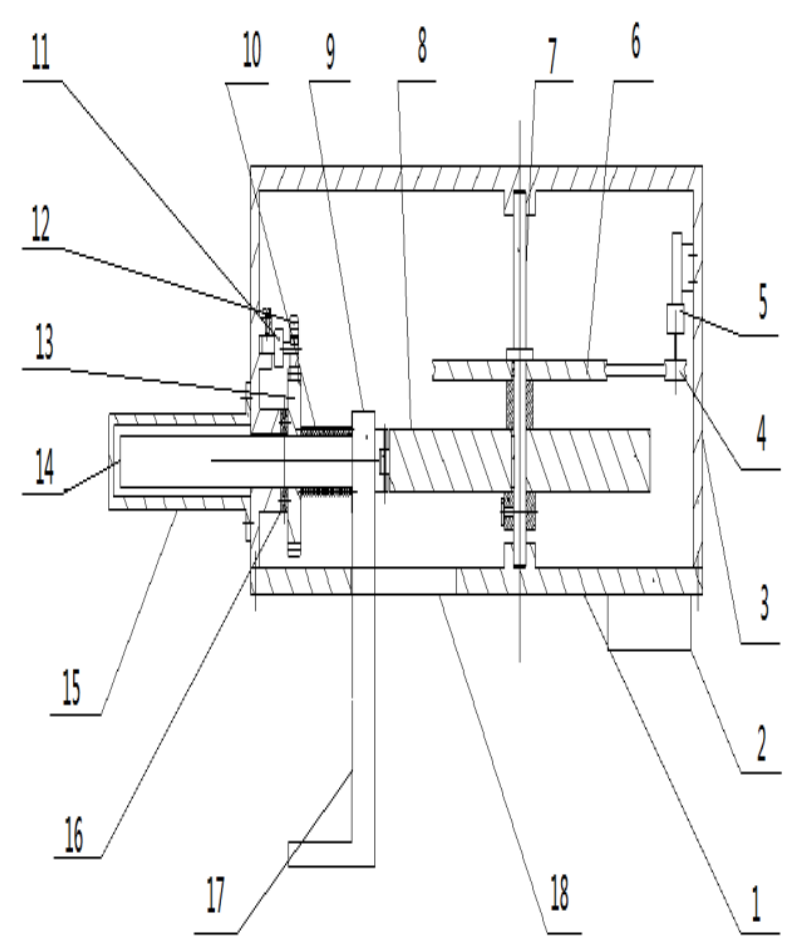

Figure 1. General structure

In figure 1, 1-- opening, 2-- tank cover, 3-- slot machine, 4-- tank, 5-belt pulley, 6-- 1st electric motor, 7-- belt pulley, 8-- main shaft, 9-- cam, 10-- lower arm, 11-- spring, 12-- 2nd reciprocating motor, 13-- pinion, 14-- Gearwheel, 15-- upper arm, 16-- upper tank cover, 17-- bearing, 18-Arm.

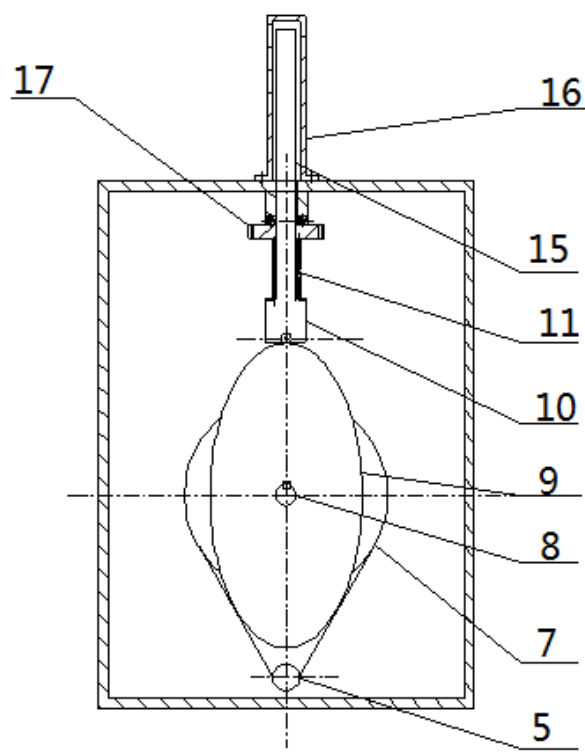

Figure 2. Left view

In figure 2,5. belt pulley, 7. belt pulley, 8. main shaft, 9. cam, 10 lower arm, spring, 15. upper arm, 16. upper tank cover, 17. Bearing.

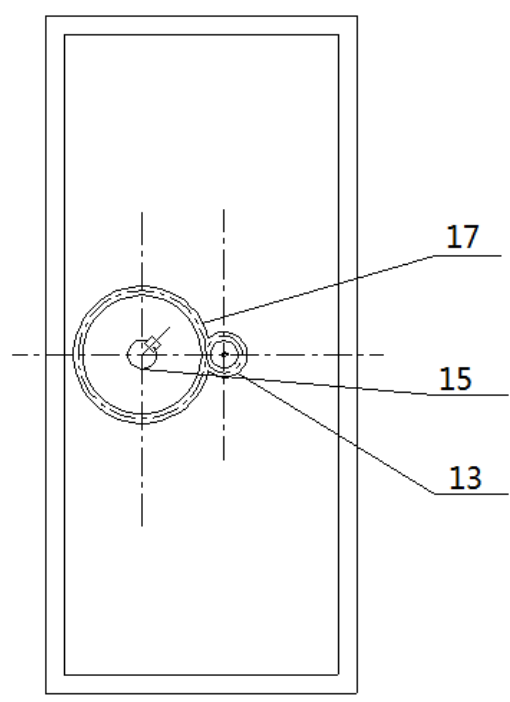

Figure 3. Vertical view

In figure 3,13. pinion, 15. upper arm, 17. Bearing.

\section{CONCLUSIONS}

(1) A set of simple mechanical transmission structure economizes manpower and resources.

(2) Simple structure and easy maintenance.

(3) Applying safe materials, waterproof and electric bonding.

The scientificity of the technological innovation in this design: when the coin is put in, the motor starts rotating, driving the belt pulley to run, thus, the cam rolls to move the arm up and down. With PLC control, the 1st electric motor stops move and the reciprocating motor starts, the pinion drives the gearwheel to make the arm move right to left.

\section{Practical Application and Significance}

(1) Efficiency is improved by designing a machine to replace manpower.

(2) It features high performance and low energy consumption. Once going on to the market, it will be wellreceived. If it is put into industrial production, it will bring huge economic profits and draw lots of attention in the society.

(3) The coin-operated back rub machine reaches the goal of high efficiency and low energy consumption, which conforms to the demands of living quality of people. Therefore, it will receive wide market prospect.

\section{REFERENCES}

[1] Liu Meilin, Liu Zhende. Introduction to Mechanical Design [M] Beijing: Science Press, 2005.

[2] Cheng Daxian. Mechanical Design Handbook [M]. 4th Edition. Volume 1. Beijing: Chemical Industry Press, 2002.

[3] Kang Fenghua, Zhang Lei. Mechanical Design Fundamentals [M]. Beijing: Metallurgical Industry Press 2011, 8:26-35.

[4] Gao Zhi,Liu Ying. Mechanical innovation design. Tsinghua University press. 2009

[5] Yang Jiajun. The innovative design of mechanical system. Huazhong University of science and Technology Press. 2000.1

[6] Zhang Chunlin. Mechanical innovation design. Beijing: Mechanical Industry Press. 2007

[7] Jian-qi zou, ya-ping cui, Su Tiejian, sinar etc. Material mechanics [M]. Beijing: tsinghua university press, 2007. 
[8] Kang Fenghua, zhang lei. Mechanical design basic tutorial [M].

Beijing: metallurgical industry press, 2011, 8:26-35. 